${ }^{1}$ Ph.D. Candidate of Health Education and Health Promotion, Department of Health Education and Health Promotion, Faculty of Medical Sciences, Tarbiat Modares University, Tehran, Iran. Email:a.goodarzy@modares.ac.ir

${ }^{2}$ Professor, Department of Health Education and Health Promotion, Faculty of Medical Sciences, Tarbiat Modares University, Tehran, Iran

a Professor, Department of Health Education and Health Promotion, Faculty of Medical Sciences, Tarbiat Modares University, Tehran, Iran. Email: Tavaffian@modares.ac.ir

4 Professor of Population Health Family and Schools Office, Ministry of Health and Medical Education, Tehran Iran.Email: meslami@mohme.gov.ir

Corresponding author: Alireza Heidarnia

Faculty of Medical Sciences, Tarbiat Modares University, Tehran, Iran Hidarnia@modares.ac.ir Phone: 982182883817 Fax: 982182883817

Mobile: 09122344145

Received: April 20, 2018

Accepted: September 21, 2018

\section{Evaluation of Decayed, Missing and Filled Teeth (DMFT) Index in the 12 Years Old Students of Tehran City, Iran}

\author{
Azam Goodarzi', Alireza Heidarnia ${ }^{2 \star}$, Sedigheh Sadat \\ Tavafian ${ }^{3}$, Mohammad Eslami
}

Aim: The main aim of this study was to Evaluate of Decayed, Missing and Filled Teeth (DMFT) Index in 12 Year Old Students of Tehran City, and to identify related factors that affect dental caries within this group. Methods: A crosssectional survey was conducted among students of 12 years old in Tehran, Iran. Dental caries status was assessed in terms of decayed teeth (DT), filled teeth (FT) and decayed, missing and filled teeth (DMFT). "Data were analysed using SPSS version 22; a multivariate regression analysis was used to determine statistically significant associations between DMFT and other variables $(p<0.05)$. Results: A total of 416 respondents participated in the study. The mean age of the students was $10.94(S D=0.628)$ years, and the mean DMFT was $1.03(\mathrm{SD}=1.41)$. So that, in this study DT $(0.53 \pm 0.95)$ had the highest and MT $(0.14 \pm 0.47)$ had the lowest mean. A multivariate regression analysis model results showed a significant relation between high DMFT scores and such variables as increasing age, lower levels of mother's education, higher family income, lower frequency of tooth brushing and dental flossing, having a history of no visits to the dentist $(P<0.05)$. Conclusion: The current study shows that Iranian female students have a poor oral health behavior, as very few subjects use dental floss on a regular basis. Although there appeared to be a significant relationship between caries scores and demographic factors such as age and socio-behavioral variables include family income, the level of mothers' education, the frequency of dental brushing and flossing, and both the frequency and type of visit to a dentist.

Keywords: Oral health. Dental caries. Students. 


\section{Introduction}

Oral health has a key role in public health and well-being of people, also base framework is in health ${ }^{1}$. Prevalence of dental caries is significantly increasing particularly among adolescents ${ }^{2}$. Although oral health of children has been improving in the present day, tooth caries still remains a public health problem, even though it is preventable $e^{3}$. According to numerous studies published in world on the importance of oral health, the World Health Organization (WHO) has emphasized on importance of oral health ${ }^{4 \cdot 6}$. On the other hand, poor oral hygiene is the cause of many diseases, also brings serious social and physical problems to each person ${ }^{1}$. Two highly prevalent dental diseases that both have significant impacts on people's life, especially children and adolescents are developmental defects of enamel (DDE) and dental caries ${ }^{7}$. Worldwide, $60-90 \%$ of school children and nearly $100 \%$ of adults have dental cavities. The highest prevalence is in Asia and in Latin America ${ }^{8}$. The highest age at risk for oral diseases is in the age range of 11-14 years ${ }^{9}$. This age is especially important as it is the age at which children, generally, leave the primary school ${ }^{10}$. Therefore, in many countries, it is the last age at which a reliable sample maybe obtained easily through the school system ${ }^{11}$. A number of studies have shown that demographic characteristics such as education of parents and family income affect oral health behaviors ${ }^{12-16}$. Oral and dental diseases are closely related to lifestyle; for example, low sugar intake, regular brushing, and regular dental check-ups diagnosing oral diseases may help to improve the general health ${ }^{1}$. Indeed, poor oral health causes limit individual's activities in adolescents as they lose an estimated more than 50 million hours of school time each year, which can greatly affect their performance and success of at school17,18. WHO goals include an average decay, missing, and filling tooth (DMFT) of not more than 3 in 2000 and not more than 1.0 in 2010 at the age of $12^{19}$. The mean value of DMFT among 12-year-old children in the world is 1.61. These indexes in Europe, Africa, America and West Pacific are reported to be 2.57, 1.3, 2.76, and 1.48 , respectively ${ }^{20}$. Based on WHO (2005), the best index of DMFT is 1 among 12 -year-old children all over the world ${ }^{19}$. In the eastern Mediterranean region, which also includes Iran, the mean number of decay missing teeth (DMT) is the highest in the Mediterranean region ${ }^{21}$. Unfortunately, since Iran does not have a good database on oral health and duration of treatment for oral diseases is long ${ }^{22}$. Oral health status assessment of adolescents is particularly important since treatment for oral diseases is long. Some dental concerns may not be obvious to adolescence; therefore, it is important that adolescents or their parents schedule routine dental visits. In this way, teens will undergo a complete examination to detect and diagnose any unknown dental concerns. Therefore, this study evaluted the status of dental caries in a sample of Iranian students aged from 10 to 12 years in Tehran, and to identify related factors that affect dental caries within this group.

\section{Materials and Methods}

The study was cross-sectional, which was conducted on the grade five female students (10-12 years old) of governmental schools in Tehran (Capital of Iran) in December 2016 for two months. To obtain samples from among the 41110 female students (grade five) 
studying in this city, a two- stage random cluster sampling method was used. In the first stage, from 20 education regions in Tehran, 10 regions $(1,4,5,9,10,11,12,13,16$ and, 17) were randomly selected. In the second stage, 416 students having above mentioned criteria were randomly selected from each school based on the population share and the number of schools and students of each school in each region (Figure 1).

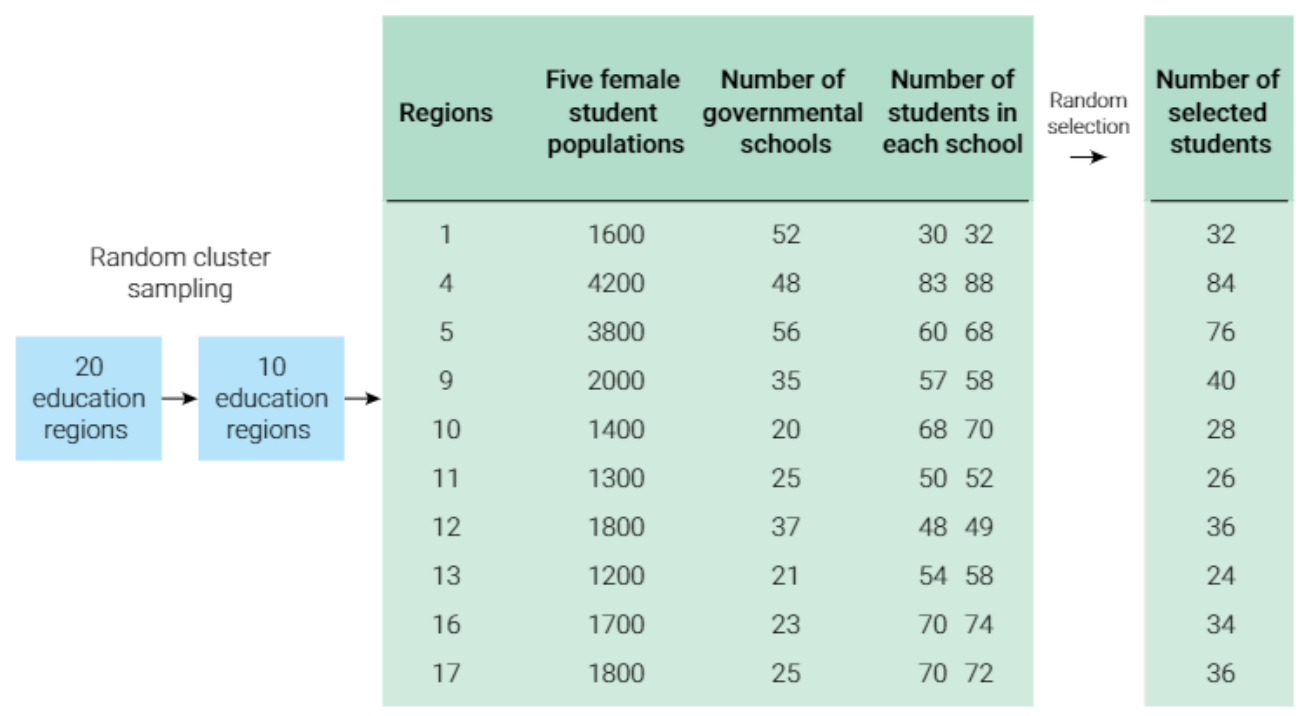

Figure 1. Sampling method in 20 educational districts of Tehran

The inclusion criteria were including fifth-grade female student (aged 10-12 years), studying in governmental schools, and having a signed consent from the child's parent or legal guardian.

In each school, the selected students were asked to respond to the study questionnaire. The researcher was present while completing the questionnaire to help the students. The students were explained that if they answer honestly, this would help the researchers achieve proper information and improve knowledge. The Ethic's Committee of Tarbiat Modares University and the organization for education approved the study in Tehran in 2016. Consent was obtained from both of parents and authorities. The questionnaire comprised some questions including age, father and mother's level of education, family income, dental visits, and frequency of tooth brushing and dental flossing. The father and mother's level of education was assessed in terms of the years of education (illiterate/primary school, secondary school/high school/diploma, higher than diploma). The monthly family income was measured using a four-point scale [1 = low (0-400\$), 2 = appropriate (400$800 \$), 3=$ well (800-1000\$), 4=excellent (>1000\$]. The frequency of tooth brushing was assessed on a two-point scale( 1 = brushing less than twice a day, 2 = brushing twice a day or more), use of dental floss daily ( 1 = dental floss once a week or less than once a day, 2 = dental floss once a day or more), and reasons for visiting dentist (1 = decay/pain/break, 2 =six months check).DMFT in the students were assessed 
by a dentist, and the intra reliability of the examiner was assessed by using the kappa statistics, which was $92 \%$ for decayed, missed, and filled teeth (DMFT).Statistical analysis was performed by SPSS, version 22.0. To compare two groups of student's unpaired t-test was used. If there were more than two groups, a one-way ANOVA followed by a Tukey's test was performed for assessment of group comparison. Finally, a multivariate regression analysis was performed to estimate the linear relation between dependent variables DMFT and various independent variables (age, mother and father's level of education, family income, tooth brushing, dental flossing, and the time since the last dental visit).

\section{Results}

The study population 416 grade five females (aged 10-12 years), with a mean of age was $10.94 \pm 0.628$ years. Most of father's (50.5\%) and mother's (51.0\%) education level was secondary school / high school / diploma. The demographic characteristics of the study population are shown in Table1. The mean DMFT was $1.03(\mathrm{SD}=1.41$. So that, in this study DT $(0.53 \pm 0.95)$ had the highest and MT $(0.14 \pm 0.47)$ had the lowest mean. Based on the results givenTable 1 , age of students had significant effect on the DMFT value, as with increasing age the DMFT value increased $(P<0.05)$. The differences between age were seen for all of the components of DMFT with the exception of Missing Teeth $(M T)(P<0.05)$. Also, those students who live in a family with a higher than diploma education level's parents had a lower incidence of caries compared with those living in a family with a lower or mode-rate education level 's parents, this difference is seen in the MT and DMFT components $(P<0.05)$ (Table 2). On the other hand, Filling Teeth (FT) was significantly elevated among children living in a family with well or excellent income compared with students living in a family with lower income $(P<0.05)$ (Table 2). Table 3 shows that DMFT and all its components were significant differences between those who were brushing twice a day or more and those who were brushing less than twice a day. So all DMFT components were higher in the students who brushed their teeth less than twice a day $(P<0.05)$. When assessing the use of dental floss, our study shows that only $19.5 \%$ use dental floss once a day or more, while $80.5 \%$ refer using dental floss sometimes. Moreover, DMFT index and its components exception of Filling Teeth (FT) with respect flossing habits had significantly different $(P<0.05)$. The incidence of caries in subjects who sometimes flossed was approximately thirty times that of individuals who flossed once a day or more, as demonstrated in Table $3(P<0.05)$. The independent t-test results showed that visiting a dentist every six months was significantly related to DMFT and all its components with the exception of FT $(P<0.01)$. Table 3 shows that the mean DMFT values of the students that visiting the dentist with the reason of decay/pain/break, was significantly higher compared to those who visit the dentist every six month $(P<0.001)$. A multivariate regression analysis model results showed that factors related to DMFT include: age) $\mathrm{P}<0.01$ ), mother's education level $(P<0.05)$, family income $(P<0.001)$, tooth brushing and use of dental floss) $P<0.01)$, reasons for visiting dentist $(P<0.05)$. Table 4 demonstrates that all factors of relevant with DMFT had a negative effect on DMFT, except age, and family income variables. 
Table1. Mean caries indices in relation to demographic characteristics (age, parents 'education levels, and family income)

\begin{tabular}{|c|c|c|c|c|c|c|}
\hline & \multirow{2}{*}{$\mathrm{N}$} & \multirow{2}{*}{$(\%)$} & DT & MT & $\mathrm{FT}$ & DMFT \\
\hline & & & Mean(SD) & Mean(SD) & Mean(SD) & Mean(SD) \\
\hline \multicolumn{7}{|l|}{ Age } \\
\hline 10 & 94 & $(22.6)$ & $0.29(0.82)$ & $0.106(0.40)$ & $0.14(0.54)$ & $0.510(1.06)$ \\
\hline 11 & 251 & $(60.3)$ & $0.60(1.00)$ & $0.14(0.46)$ & $0.43(0.89)$ & $1.18(1.48)$ \\
\hline 12 & 71 & (17.1) & $0.63(0.91)$ & $0.19(0.57)$ & $0.23(0.59)$ & $1.19(1.44)$ \\
\hline
\end{tabular}

$($ mean $\pm S D)=10.94 \pm 0.628$

Father's education level

\begin{tabular}{|c|c|c|c|c|c|c|}
\hline Illiterate / Primary school & 62 & $(14.9)$ & $0.96(1.29)$ & $0.19(0.53)$ & $0.43(0.84)$ & $1.90(1.80)$ \\
\hline $\begin{array}{l}\text { Secondary school / } \\
\text { High school /Diploma) }\end{array}$ & 210 & $(50.5)$ & $0.48(0.88)$ & $0.15(0.44)$ & $0.26(0.68)$ & $0.90(1.32)$ \\
\hline Higher than diploma & 144 & $(34.6)$ & $0.43(0.84)$ & $0.11(0.48)$ & $0.39(0.91)$ & $0.85(1.22)$ \\
\hline \multicolumn{7}{|l|}{ Mother's education level) } \\
\hline Illiterate/Primary school & 60 & $(14.4)$ & $1.03(1.42)$ & $0.16(0.52)$ & $0.35(0.91)$ & $2.06(1.97)$ \\
\hline $\begin{array}{l}\text { Secondary school / } \\
\text { High school /Diploma }\end{array}$ & 200 & $(48.1)$ & $0.49(0.87)$ & $0.16(0.48)$ & $0.31(0.74)$ & $0.88(1.24)$ \\
\hline Higher than diploma & 156 & $(37.5)$ & $0.40(0.76)$ & $0.11(0.43)$ & $0.35(0.80)$ & $0.82(1.20)$ \\
\hline \multicolumn{7}{|l|}{ Family income } \\
\hline Low (39) & 39 & $(9.4)$ & $0.25(0.78)$ & $0.02(0.16)$ & $0.10(0.44)$ & $0.41(1.09)$ \\
\hline Appropriate & 166 & $(39.9)$ & $0.54(1.05)$ & $0.07(0.25)$ & $0.24(0.61)$ & $0.76(1.26)$ \\
\hline Well & 113 & $(27.2)$ & $0.57(0.89)$ & $0.21(0.61)$ & $0.38(0.88)$ & $1.15(1.34)$ \\
\hline Excellent & 98 & $(23.6)$ & $0.60(0.91)$ & $0.23(0.60)$ & $0.54(0.98)$ & 1.59 (1.64) \\
\hline Total & 416 & (100) & $0.53(0.95)$ & $0.14(0.47)$ & $0.33(0.79)$ & $1.03(1.41)$ \\
\hline
\end{tabular}


Table 2. Mean difference caries indices in relation to age, parents 'education levels, and family income

\begin{tabular}{|c|c|c|c|c|c|}
\hline & & DT & MT & $\mathrm{FT}$ & DMFT \\
\hline & & MD & MD & MD & MD \\
\hline \multicolumn{6}{|c|}{ Age (years) } \\
\hline \multirow[t]{2}{*}{10} & 11 & $-0.303^{\star}$ & -0.037 & $0.285^{\star}-$ & $-0.672^{\star}$ \\
\hline & 12 & -0.335 * & -0.090 & -0.090 & -0.686 * \\
\hline \multirow[t]{2}{*}{11} & 10 & $0.303^{*}$ & 0.037 & $0.285^{\star}$ & $0.672^{\star}$ \\
\hline & 12 & -0.322 & -0.053 & 0.194 & -0.013 \\
\hline \multirow[t]{2}{*}{12} & 10 & 0.335 * & 0.090 & 0.090 & $0.686^{*}$ \\
\hline & 11 & 0.032 & 0.053 & -0.194 & 0.013 \\
\hline \multicolumn{6}{|c|}{ Father's education level } \\
\hline \multirow[t]{2}{*}{ Illiterate/Primary school } & $\begin{array}{l}\text { Secondary school / } \\
\text { High school /Diploma }\end{array}$ & $0.482^{\star}$ & 0.041 & 0.168 & $1.003^{*}$ \\
\hline & Higher than diploma & $0.537^{*}$ & 0.082 & 0.039 & $1.049^{*}$ \\
\hline \multirow[t]{2}{*}{$\begin{array}{l}\text { Secondary school /High } \\
\text { school /Diploma }\end{array}$} & Illiterate/Primary school & $-0.482^{\star}$ & -0.041 & -0.168 & $-1.003^{*}$ \\
\hline & Higher than diploma & 0.055 & 0.041 & -0.129 & 0.0458 \\
\hline \multirow[t]{2}{*}{ Higher than diploma } & Illiterate/Primary school & $-0.537^{\star}$ & -0.082 & -0.039 & $-1.049 *$ \\
\hline & $\begin{array}{l}\text { Secondary school / } \\
\text { High school /Diploma }\end{array}$ & -0.055 & -0.041 & 0.129 & -0.0458 \\
\hline \multicolumn{6}{|c|}{ Mother's education level } \\
\hline \multirow[t]{2}{*}{ Illiterate/Primary school } & $\begin{array}{l}\text { Secondary school / } \\
\text { High school /Diploma }\end{array}$ & $0.538^{*}$ & 0.006 & 0.035 & $1.181^{*}$ \\
\hline & Higher than diploma & $0.629 *$ & 0.051 & -0.008 & 1.239 * \\
\hline \multirow[t]{2}{*}{$\begin{array}{l}\text { Secondary school /High } \\
\text { school /Diploma }\end{array}$} & Illiterate/Primary school & $-0.538 *$ & -0.006 & -0.035 & $-1.181^{*}$ \\
\hline & Higher than diploma & 0.091 & 0.044 & -0.043 & 0.058 \\
\hline \multirow[t]{2}{*}{ Higher than diploma } & Illiterate/Primary school & $-0.629 *$ & -0.051 & 0.008 & $-1.239 *$ \\
\hline & $\begin{array}{l}\text { Secondary school / } \\
\text { High school /Diploma }\end{array}$ & -0.091 & -0.044 & 0.043 & -0.058 \\
\hline \multicolumn{6}{|c|}{ Family income } \\
\hline \multirow[t]{3}{*}{ Low } & Appropriate & -0.285 & -0.046 & -0.138 & -0.354 \\
\hline & Well & -0.033 & $-0.186^{\star}$ & -0.277 & $-0.749 *$ \\
\hline & Excellent & -0.059 & $-0.209^{*}$ & $-0.438^{\star}$ & $-1.18^{*}$ \\
\hline \multirow[t]{3}{*}{ Appropriate } & Low & 0.318 & 0.046 & 0.138 & 0.354 \\
\hline & Well & 0.033 & $-0.140 *$ & -0.139 & $-0.394^{\star}$ \\
\hline & Excellent & -0.026 & $-0.162^{*}$ & $-0.299^{*}$ & $-0.826^{*}$ \\
\hline \multirow[t]{3}{*}{ Well } & Low & 0.345 & $0.186^{\star}$ & 0.277 & $0.749 *$ \\
\hline & Appropriate & 0.059 & $0.140 *$ & 0.139 & $0.394^{*}$ \\
\hline & Excellent & 0.026 & $-0.022 *$ & -0.160 & $-0.432^{\star}$ \\
\hline \multirow[t]{3}{*}{ Excellent } & Low & 0.345 & $0.209 *$ & $0.438 *$ & $1.181^{*}$ \\
\hline & Appropriate & 0.059 & $0.162^{\star}$ & $0.299 *$ & $0.826^{\star}$ \\
\hline & Well & 0.026 & 0.022 & 0.160 & $0.432^{\star}$ \\
\hline
\end{tabular}

* The mean difference is significant at the 0.05 level 
Table 3.Dental caries incidence and its component factors e.g. frequency of brushing and flossing, dental visits

\begin{tabular}{|c|c|c|c|c|c|c|}
\hline & \multirow{2}{*}{$\mathrm{N}$} & \multirow{2}{*}{$(\%)$} & DT & MT & FT & DMFT \\
\hline & & & Mean (SD) & Mean(SD) & Mean (SD) & Mean (SD) \\
\hline \multicolumn{7}{|l|}{ Tooth brushing } \\
\hline $\begin{array}{l}\text { brushing less than twice } \\
\text { a day }\end{array}$ & 214 & $(51.4)$ & $0.630(1.015)$ & $0.191(0.535)$ & $0.425(0.878)$ & $1.317(1.535)$ \\
\hline $\begin{array}{l}\text { brushing twice a day } \\
\text { or more }\end{array}$ & 202 & $(48.6)$ & $0.440(0.886)$ & $0.094(0.394)$ & $0.242(0.680)$ & $0.732(1.216)$ \\
\hline P-value & & & $0.042^{\star}$ & $0.034^{\star}$ & $0.018^{*}$ & $0.000 *$ \\
\hline \multicolumn{7}{|l|}{ Use of dental floss } \\
\hline $\begin{array}{l}\text { using dental } \\
\text { floss sometimes }\end{array}$ & 335 & $(80.5)$ & $0.606(1.014)$ & $0.164(0.507)$ & $0.367(0.822)$ & $1.167(1.501)$ \\
\hline $\begin{array}{l}\text { dental floss once a day } \\
\text { or more }\end{array}$ & 81 & $(19.5)$ & $0.025(0.607)$ & $0.061(0.289)$ & $0.209(0.646)$ & $0.481(0.807)$ \\
\hline P-value & & & $0.000^{*}$ & $0.017^{\star}$ & 0.065 & $0.00 *$ \\
\hline \multicolumn{7}{|l|}{ Reasons for visiting dentist(n) } \\
\hline Decay/Pain/Break & 265 & $(63.7)$ & $0.660(1.028)$ & $0.184(0.557)$ & $0.354(0.784)$ & $1.275(1.496)$ \\
\hline six months check & 151 & $(36.3)$ & $0.324(0.779)$ & $0.072(0.260)$ & $0.304(0.808)$ & $0.609(1.160)$ \\
\hline P-value & & & $0.000^{*}$ & $0.006^{\star}$ & 0.540 & $0.000 *$ \\
\hline
\end{tabular}

* The mean difference is significant at the 0.05 level

Table 4. Multivariate regression analyses of the dependant variable DMFT against socio demographic and behavioral factors

\begin{tabular}{|c|c|c|c|c|c|}
\hline & \multirow{2}{*}{$\mathrm{B}$} & \multirow{2}{*}{ B } & \multicolumn{2}{|c|}{$\mathrm{Cl}$} & \multirow{2}{*}{ P-value } \\
\hline & & & Lower & Upper & \\
\hline Age & 0.306 & 0.136 & 0.110 & 0.502 & 0.002 \\
\hline Father's education level & -0.157 & -0.075 & -0.376 & 0.062 & 0.160 \\
\hline Mother's education level & -0.279 & -0.133 & -0.491 & -0.062 & 0.012 \\
\hline Family income & 0.426 & 0.283 & 0.296 & 0.556 & 0.00 \\
\hline Tooth brushing & -.392 & -0.138 & -0.658 & -0.127 & 0.004 \\
\hline Use of dental floss & -0.447 & -0.125 & -0.773 & -0.120 & 0.007 \\
\hline Reasons for visiting dentist & -0.328 & -0.111 & -0.604 & -0.052 & 0.020 \\
\hline
\end{tabular}

* The mean difference is significant at the 0.05 level, B, standardized regression coefficients; $\mathrm{B}$, unstandardized regression coefficients; $95 \% \mathrm{Cl}, 95 \%$ confidence interval.

\section{Discussion}

The present study conducted amongst students in Tehran (Capital of Iran) a developing country, showed that oral health behaviors including brushing less than twice a day, dental floss once a day or more, six months check and demographic characteristics contains age, mother's education, and family income play important role in adopting a desirable health behavior among young adolescents. Currently, Most of 12 years old Iranian students have been diagnosed them DMFT index with oral health certificates in school. This will help to determine the longitudinal analysis of oral health related trends of decay index and its components in this age group in Iran in future years. The findings from this study showed that the mean DMFT values in the 
grade five female Iranian students were $1.03 \pm 1.41$. These results are consistent with a DMFT of 1.23 that reported in findings of Farhadi et al. ${ }^{23}$. Also in accordance with a DMFT of $1.00 \pm 1.41$ reported by Amirabadi et al. ${ }^{24}$, among in 8-12 Year Old Students of Zahedan City, Iran. The mean DMFT index in this research was much lower than the index reported by Pakpour $2.43 \pm 1.741$. Perhaps reason for this difference could be the study of Pakpour were done almost 5 years ago prior to this study. The DMFT index was in other Middle Eastern countries such as Libya $1.68 \pm 1.86^{25}$, and Saudia Arabi $1.53 \pm 1.86^{26}$. Maybe the reason of the low score DMFT in Iranian students is that elementary schools students, use little of fluoride varnish_twice a year_almost 3 years before this study. In Asia, the DMFT index for children at the age of 12 years in Singapore in 2011 was the lowest at 0.6 , followed by Japan with a score of 1.4. "Except of Cambodia's score of 3.5 and the Philippine's score of 3.3 in 2011, the DMFT indices for the various Asian countries for children at the age of 12 years are all lower than 3.0". In addition, according to the findings obtained from the 11 elementary schools in Hualien County, Taiwan DMFT index for permanent dentition was $0.68^{27}$. In terms of demographic characteristics significant differences $(p<0.05)$ were found among age, mother's education, and family income of students in the prevalence of dental caries and $\square$ DMFT index. Family income and age had a positive effect and mother's education level had negative effect on DMFT values. In terms of age, significant differences $(p<0.05$ ) were found among 10 ages with students that their age was 11 and 12 years old in the prevalence of dental caries and $\mathrm{D}$ DMFT. It seems that because elementary schools students are in a period of mixed dentition and will gradually lose their deciduous teeth and develop permanent teeth over time, this leads to a reduction in the dental caries status of 10 ages schoolchildren with mixed dentition compared with 11 and 12 years old. These findings are consistent with the study of Pakpour ${ }^{1}$. Moreover, the students who their mothers had education level higher had significantly lower levels of DMFT index than those that mothers had education level lower. Our assumed, therefore that mothers that had education level higher probably indicate a more oral health behavior, most likely their teeth more brushing, perhaps use of dental floss more, and they do each six months check their teeth by a dentist. A number of studies confirmed our results $1,13,19,21,28-30$. The data collected in this study shows that high family income was related to student's DMFT index. Since the monthly income of family play an important role in the formation of their adolescent's oral health habits and it is assumed possible that Families with a high-income use more sugar and sweets than others with a lower income that this can a catalyst is in caries of teeth and increase DMFT index. A number of studies reported favorable results ${ }^{1,22}$. On the other hand, oral health behaviors including: tooth brushing, use of dental floss, and six months check by a dentist may be related with DMFT score. The frequency of oral health behaviors had a negative effect on DMFT scores (brushing less than twice a day, dental floss once a day or more, six months check). Almost more than half of the samples (51.4\%) reported that their teeth brushed of less than twice a day; the mean DMFT of them was almost twice of those who brushed more than twice a day. Also less than one-fifth of the study sample (19.5\%) reported that they use of dental floss once a day or more, so that their mean DMFT value was almost one- third of those who use of dental floss sometimes. Moreover almost slightly more than onethird of the samples $(36.3 \%)$ had their teeth check every six months by a dentist that 
their mean DMFT score was Half that of those who came to the dentist when they had decay/pain/break. In actuality, these results indicate that Iranian adolescents had poor oral health behavior particularly in use of dental floss and this requires long time plan in the use of dental floss in Iranian adolescents, which should start of primary schools. "The major limitation of this study was: all participants were female students in Tehran (Capital of Iran), so caution is needed to generalizing the findings to male students or even other populations".. Further studies with similar age groups are necessary for confirming the findings. Self-reporting is another limitation in order to generalize the findings.

In conclusion, the present study revealed that Iranian female adolescents represent behaviors that outcome are poor oral health, especially due to infrequent use of dental floss and type of visit to a dentist.

\section{Acknowledgement}

This is part of a PhD dissertation of the first author at Department of Health Education and Promotion, Faculty of Medicine, Tarbiat Modares University, Tehran, Iran. Hereby, we appreciate the cooperation of all participating students and the respected authorities of schools supervised by the Ministry of Education in Tehran.

\section{References}

1. Pakpour AH, Hidarnia A, Hajizadeh E, Kumar S, Harrison AP. The status of dental caries and related factors in a sample of Iranian adolescents. Med Oral Patol Oral Cir Bucal. 2011 Sep 1;16(6):e822-7.

2. Bagramian RA, Garcia-Godoy F, Volpe AR. The global increase in dental caries. A pending public health crisis. Am J Dent. 2009 Feb;22(1):3-8.

3. Lukssamijarulkul N, Panza A. Oral health problems among children in selected primary schools in Bangkok, Thailand. J Health Res. 2016;30(Suppl 1):17-25.

4. Akrad ZT, Beitollahi J, Khajetorab A. DMFT (Decayed, Missing, Filled, Teeth) Oral Health Index in Sweets and Cable Industry Workers (2006). Iranian J Public Health. 2006;35(2):64-8.

5. Aggeryd T. Goals for oral health in the year 2000: cooperation between WHO, FDI and the national dental associations. Int Dent J. 1983 Mar;33(1):55-9.

6. Murray Thomson W. Epidemiology of oral health conditions in older people. Gerodontology. 2014 Feb;31 Suppl 1:9-16. doi: 10.1111/ger.12085.

7. Vargas-Ferreira F, Ardenghi TM. Developmental enamel defects and their impact on child oral healthrelated quality of life. Braz Oral Res. 2011 Nov-Dec;25(6):531-7.

8. Yang F, Zhang Y, Yuan X, Yu J, Chen S, Chen Z, et al. Caries experience and its association with weight status among 8-year-old children in Qingdao, China. J Int Soc Prev Community Dent. 2015 Jan-Feb;5(1):52-8. doi: 10.4103/2231-0762.151978.

9. Sharma V, Gupta N, Arora V, Gupta P, Mehta N. Caries Experience in Permanent Dentition among 11-14 Years Old School Children in Panchkula District (Haryana) India. Int J Sci Study. 2015 Apr;3(1):112-5. Doi: 10.17354/ijss/2015/167.

10. World Health Organization. Oral health surveys: basic methods. 5. ed. World Health Organization; 2013.

11. Esmaeilzadeh S, Abbasi A, Nikniaz S, Fathi B, Saeli E. Evaluation of oral and dental health among 12 year-old students in Jolfa, East Azerbaijan. Depict Health. 2017 Jan;7(4):30-6. 
12. Zare MS, Noroozi A, Tahmasebi R. Factors influencing tooth brushing behaviour based on health belief model among Bushehr Primary School 5th \& 6th grade students. Hayat. 2013 Nov;19(2):67-78.

13. Kasmaei P, Amin Shokravi F, Hidarnia A, Hajizadeh E, Atrkar-Roushan Z. survey of predictive factors on brushing behavior according to the three main motivational constructs among female students of primary schools. J Guilan Univ Med Sci. 2014 Oct 15;23(91):16-22.

14. Rajab LD, Petersen PE, Bakaeen G, Hamdan MA. Oral health behaviour of schoolchildren and parents in Jordan. Int J Paediatr Dent. 2002 May;12(3):168-76.

15. Mbawalla HS, Masalu JR, Åstrøm AN. Socio-demographic and behavioural correlates of oral hygiene status and oral health related quality of life, the Limpopo-Arusha school health project (LASH): A cross-sectional study. BMC Pediatr. 2010 Nov 30;10:87. doi: 10.1186/1471-2431-10-87.

16. Bayat-Movahed S, Samadzadeh H, Ziyarati L, Memary N, Khosravi R, Sadr-Eshkevari PS. Oral health of Iranian children in 2004: a national pathfinder survey of dental caries and treatment needs. East Mediterr Health J. 2011 Mar;17(3):243-9.

17. Crowley E, O’Brien G, Marcenes W. School league tables: a new population based predictor of dental restorative treatment need. Community Dent Health. 2003 Jun;20(2):78-82.

18. Gift HC, Reisine ST, Larach DC. The social impact of dental problems and visits. Am J Public Health. 1992 Dec;82(12):1663-8. Erratum in: Am J Public Health 1993 Jun;83(6):816.

19. Petersen PE, Bourgeois D, Ogawa H, Estupinan-Day S, Ndiaye C. The global burden of oral diseases and risks to oral health. Bull World Health Organ. 2005 Sep;83(9):661-9.

20. Hashemian M, Falahi A, Tavakoli G, Zarezadeh Y, NematShahrBabaki B, Rahaei Z. Study of the Impact of education on interdental cleaning behaviour based on the transtheoretical model. Oral Health Prev Dent. 2012;10(1):37-46.

21. Saied-Moallemi Z, Murtomaa H, Tehranchi A, Virtanen J. Oral health behaviour of Iranian mothers and their 9-year-old children. Oral Health Prev Dent. 2007;5(4):263-9.

22. Jürgensen N, Petersen PE. Oral health and the impact of socio-behavioural factors in a cross sectional survey of 12-year old school children in Laos BMC Oral Health. 2009 Nov 16;9:29. doi: 10.1186/1472-6831-9-29.

23. Farhadi F, Miab HF, Zarandi A. Determination of Decayed, Missing and Filled Teeth (DMFT) index in the 12 years old children of Hadishahr province from Iran. Ann Appl Bio-Sci. 2016 Aug 10;3(3):A223-6.

24. Amirabadi F, Bazafshan E, Dehghan J, Zazouli MA. Evaluation of DMFT index in the 8-12 years old students of Zahedan City, Iran. Iranian J Health Sci. 2015 May 15;3(2):52-60.

25. Huew R, Waterhouse PJ, Moynihan PJ, Maguire A. Prevalenceand severity of dental caries in Libyan schoolchildren. Int Dent J. 2011 Aug;61(4):217-23. doi: 10.1111/j.1875-595X.2011.00060.X.

26. Bhayat A, Ahmad MS. Oral health status of 12-year-old male schoolchildren in Medina, Saudi Arabia/ Santé bucco-dentaire chez des garçonsâgés de 12 ans à Médine (Arabiesaoudite). East Mediterr Health J. 2014 Dec 17;20(11):732-7.

27. Cheng YC, Huang HK, Wu CH, Chen CC, Yeh JI. Correlation between dental caries and diet, oral hygiene habits, and other indicators among elementary school students in Xiulin Township, Hualien County, Taiwan. Tzu Chi Med J. 2014 Dec;26(4):175-81.

28. Peng B, Petersen PE, Fan MW, Tai BJ. Oral health status and oral health behaviour of 12-year-old urban schoolchildren in the People's Republic of China. Community Dent Health. 1997 Dec;14(4):238-44.

29. Weinstein $P$, Harrison R, Benton T. Motivating parents to prevent caries in their young children: oneyear findings. J Am Dent Assoc. 2004 Jun;135(6):731-8.

30. Cianetti S, Lombardo G, Lupatelli E, Rossi G, Abraha I, Pagano S, et al. Dental caries, parents educational level, family income and dental service attendance among children in Italy. Eur J Paediatr Dent. 2017 Mar;18(1):15-18. doi: 10.23804/ejpd.2017.18.01.03. 